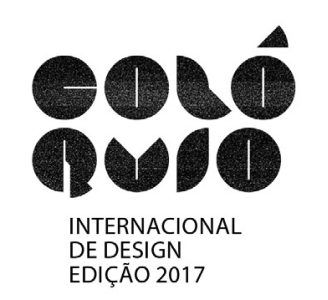

\title{
Museu virtual: espaço de interação
}

\author{
Flávia Marieta Magalhães Rigoni; \\ Maria Regina Álvares Correia Dias
}

resumo:

O desenvolvimento, a consolidação e a difusão das Tecnologias da Informação e da Comunicação impulsionaram uma revolução da cultura que fomentou profundas alterações na sociedade, tanto na velocidade de conexão das tecnologias, quanto na transformação dos modelos de produção, armazenamento, distribuição e acesso à informação. Nesse contexto, emerge o museu virtual, fruto do diálogo entre práticas museológicas e as novas tecnologias. Esses espaços com formatos e objetivos variados são compostos por uma coleção de objetos digitalizados, organizados e dispostos de forma lógica. Por meio da conectividade e da acessibilidade, ele permite ao visitante transcender os modos tradicionais de comunicação, dando-lhe uma visão dinâmica e um contato interativo com a coleção e com o espaço expositivo. Assim, centrado no patrimônio cultural material e imaterial, o museu virtual utiliza a interatividade e as técnicas imersivas com objetivos didáticos e de pesquisa para o entretenimento e a valorização da experiência do visitante. Este artigo tem caráter exploratório e emprega como procedimento técnico o levantamento bibliográfico e o estudo de caso. Ele aborda definições de museus físicos e virtuais, ciberespaço, interação e analisa como os museus romperam barreiras rígidas de distribuição e de acesso à informação. Além disso, é realizado um estudo de caso do Art Project que aborda sua origem, as tecnologias empregadas, os sistemas que o constituem, seu processo de desenvolvimento. A análise realizada confirma a relevância do projeto como um grande museu virtual que reúne em um ambiente, diversos espaços físicos virtualizados e possibilita a interação entre as obras, o espaço virtual e o visitante.

\section{palavras-chave:}

Museu virtual; tecnologia; Art Project; interação. 


\section{Introdução}

O desenvolvimento, a consolidação e a difusão das Tecnologias da Informação e da Comunicação (TICs) conduziram a grandes transformações sociais, ao trazer implicações e inovações para todas as áreas da sociedade e do conhecimento, tais como: a gestão do patrimônio cultural, a museologia e a educação. Nesse cenário, a Internet se estrutura e articula, na interface entre o virtual e as novas tecnologias, bem como o desenvolvimento de redes no ciberespaço.

Rapidamente as instituições museológicas se aperceberam das vantagens e potencialidades da internet, massiva, rápida, imediata, económica, monopolizadora do quotidiano do trabalho e do ócio, sendo que cada vez mais gente tem possibilidades de aceder às novas tecnologias ou tem à disposição recursos facilitadores para tal. A internet permite uma facilidade de atualização continua da informação e uma aproximação estratégica entre o utilizador e a instituição/bens culturais baseada na transposição das barreiras físicas, geográficas e temporais; estas acarretam uma democratização do acesso à informação e ao conhecimento e facilitam o acesso individual e descentralizado do público, de modo não presencial (PINHO, 2007, p. 4).

Quando se passa para o campo virtual, a área de ação alarga-se dando origem a múltiplos percursos interativos. Ao tentar representar o real cria-se uma nova realidade, paralela e coexistente com a primeira, que deve ser vista como um conjunto de novas visões, sobre o museu tradicional (MUCHACHO, 2005, p. 1545).

Desse modo, a aplicação de tecnologias digitais conduz a uma continua evolução do conceito de museu e de fruição do patrimônio artístico e cultural, que se tornam cada vez mais interativos, imersivos e digitais. Por estar aberto a todos e conectado às redes de informação, o museu virtual se evidencia como um instrumento de contribuição à preservação e à divulgação do patrimônio e da memória cultural, possibilitando a popularização do conhecimento.

Os museus podem tornar-se protocolos de comunicação entre diferentes identidades, comunicando a arte, a ciência e a experiência humana; e podem estruturar-se como conectores de diferentes temporalidades, traduzindo-as numa sincronia comum, mas mantendo, ao mesmo tempo, uma perspectiva histórica. Finalmente, eles podem ligar as dimensões globais e locais de identidade, o espaço e a sociedade local (CASTELLS, 2015, p. 60).

Sem fronteiras, ele é capaz de dialogar virtualmente com o visitante, dando-lhe uma visão dinâmica, multidisciplinar e um contato interativo com a coleção e com o espaço expositivo. Esse ambiente virtual torna-se um lugar de encontro, discussão e troca, no qual sua singularidade reside no modo particular de identificar, organizar, contextualizar e reconstruir referências sociais para os elementos culturais, das identidades e memórias coletivas. Seu desenvolvimento, contudo, é um processo complexo, que envolve equipes multidisciplinares e abrange aspectos técnicos, ergonômicos, sociais, culturais, funcionais, estéticos e tecnológicos.

O presente artigo tem objetivo exploratório e aborda temas relacionados ao estudo, para melhor embasa-lo. Ele emprega como procedimento técnico o levantamento bibliográfico e o estudo de caso do Art Project.

\section{Museus físicos e museus virtuais}

Os museus são sistemas de armazenamento, processamento e transmissão de mensagens culturais potencialmente interativas, dentro de um e para um determinado contexto social (CASTELLS, 2015, p. 49). Eles são, portanto, instituições de relevância social, educativa e cultural, que têm como funções estudar, preservar e divulgar diferentes tipologias de património cultural tangível e intangível.

As práticas museológicas baseadas em ações sobre o território de uma comunidade e a totalidade do seu patrimônio possibilitam a interpretação das relações do ser humano com seu ambiente e a influência da herança cultural e natural na identidade dos indivíduos e dos grupos. 
$\mathrm{Na}$ área da preservação, os trabalhos de conservação e de restauro, realizados nos âmbitos museológicos, asseguram a preservação dos bens culturais e sua consequente transmissão às gerações futuras, controlando os fatores responsáveis pela sua degradação material. Já no campo da difusão e comunicação, a exposição destaca-se como meio relevante e eficaz de diálogo, ao possibilitar o encontro entre o visitante e o objeto real que se expõe. Ademais, os museus também exercem função didática, ao desenvolverem projetos e ações de educação patrimonial e museal, que o validam como espaço educativo, de descoberta, no qual os visitantes podem aprender descobrir e experimentar.

A existência simultânea de museus físicos e eletrônicos constitui uma marca deste século no âmbito cultural contemporâneo. Embora as funções museológicas sejam as mesmas, no mundo físico e no ciberespaço, os museus apresentam características diferenciadas, segundo Loureiro (2203).

Os museus no espaço físico apresentam materialidade, ênfase na obra única, permanência, estabilidade, caráter institucional por definição, linearidade, processo de comunicação e transferência de informação unidirecional e assimétrica; tendência à separação dos polos receptor/emissor. Os museus no ciberespaço se caracterizam pela imaterialidade, ubiquidade, provisoriedade, instabilidade, caráter não necessariamente institucional, hipertextualidade, estímulo à interatividade e tendência à comunicação bi ou multidirecional (LOUREIRO, 2003, p. 172).

Na visão de Pierre Lévy, o ciberespaço abriu um novo tipo de espaço para a inserção dos Museus. Ou seja, de um tradicional espaço físico relacionado à ocupação de um território material, tangível, o museu passou a se deparar com o espaço virtual, imaterial, intangível (LÉVY, 1999).

Essa capacidade de proporcionar conectividade a vários pontos de acesso possibilita transcender métodos tradicionais de comunicação e interação com visitantes, sendo flexível com relação a suas necessidades e seus interesses. Por não haver lugar ou espaço físico, os objetos e as informações relacionadas podem ser disseminados em todo o mundo.

Fruto do diálogo entre práticas museológicas e as novas tecnologias, os museus virtuais são espaços com formatos e objetivos variados. Eles envolvem práticas que ainda estão sendo conceituadas, instigando novas reflexões teóricas, tais como as diferentes formas de diálogo entre o museu no espaço da web e os diversos públicos.

De acordo com Henriques (2004, p.11) "o museu virtual é um espaço virtual de mediação e de relação do patrimônio com os utilizadores. É um museu paralelo e complementar que privilegia a comunicação como forma de envolver e dar a conhecer determinado patrimônio".

Para Schweibenz, o museu virtual é uma coleção de objetos digitalizados, organizados e dispostos de forma lógica, sendo composto por diversos suportes. A conectividade e a acessibilidade desse ambiente permitem transcender os modos tradicionais de comunicação e de interação com o visitante. Desse modo, por não dispor de um lugar ou espaço real, seus objetos e informações podem ser amplamente difundidos (SCHWEIBENZ, 2004, p. 3).

Já na visão de Hazan (2013), o museu virtual é um produto de comunicação acessível ao público, centrado no patrimônio cultural material e imaterial, que utiliza a interatividade e técnicas imersivas com objetivos didáticos e de pesquisa para o entretenimento e para a valorização da experiência do visitante (HAZAN, 2013 apud CANOVA, 2015, p. 40).

Por essa razão, a singularidade do museu virtual, reside no seu modo particular de identificar, organizar, contextualizar e reconstruir referências sociais para os elementos culturais, das identidades e memórias coletivas, assim como de colocá-las em diálogo, como fórum, no espaço público.

\section{A relação que se estabelece na rede}

Da palavra à realidade virtual, a história da comunicação humana sempre se pautou pelo aprimoramento da expressão, transmissão e compreensão de conteúdos e ou mensagens.

$\mathrm{Na}$ década de 70, por meio da disponibilidade de novas tecnologias, Castells comenta que se desenvolve o progresso de reestruturação socioeconômica dos anos 80 , cuja utilização da tecnologia condicionou o desenvolvimento das décadas seguintes, conduzindo a era da digitalização (CASTELLS, 2000, p. 64). 
Nesse período, se iniciava a produção da fibra ótica em grande escala e a sua aplicação para transmissão de ondas eletromagnéticas em alta velocidade para longas distâncias, o que possibilitou a conexão de continentes por meio da tecnologia digital, e o estabelecimento de novas relações sociais através de múltiplos canais e formas de interação (MAGALDI, 2010, p. 29).

Essas novas tecnologias, para Lévy (2001), almejavam reduzir de modo crescente o tempo e o espaço de comunicação entre dois ou mais pontos no planeta. $\mathrm{O}$ autor defende que essas tecnologias aplicadas à vida cotidiana evidenciam a percepção da inteligência coletiva, na qual todos contribuem para a transformação através de ações ou da criação, transformação ou manutenção de valores e afetos sociais. Essas relações se estabelecem e se articulam na rede como psiquismo vivo, através de um hipertexto dinâmico, por meio de imagens, textos, depoimentos ou vídeos.

Por sua vez, Castells $(2001$, p. 7) aponta a Internet como um tecido de nossas vidas, sendo a base tecnológica para a formação organizacional da Era da Informação: a rede. Esse conjunto de nós interconectados, destaca-se como ferramentas de organização em virtude de sua flexibilidade e adaptabilidade, que a permite sobreviver e prosperar em um ambiente de constantes transformações.

A Internet, portanto, é uma rede de comunicação eletrônica que possibilita aos seus usuários acessar a informação do local ao global, sobre diversos assuntos em qualquer parte do mundo. Nessa rede o emissor e o receptor se misturam, de modo que o objeto e o sujeito se fundem através de um suporte tecnológico (MIRANDA, 2005 apud MAGALDI, 2010).

Nesse contexto emerge o ciberespaço, definido por Lévy (1999) como o espaço de comunicação aberto pela interconexão dos computadores e suas memórias, sendo a cibercultura o conjunto das expressões culturais que se dão nesse espaço.

Essa definição inclui o conjunto dos sistemas de comunicação eletrônicos, na medida em que transmitem informações provenientes de fontes digitais ou destinadas à digitalização. Insisto na codificação digital, pois ela condiciona o caráter plástico, fluido, calculável com precisão e tratável em tempo real, hipertextual, interativo e, resumindo, virtual da informação que é, parece-me, a marca distintiva do ciberespaço. Esse novo meio tem a vocação de colocar em sinergia e interfacear todos os dispositivos de criação de informação, de gravação, de comunicação e de simulação. A perspectiva da digitalização geral das informações provavelmente tornará o ciberespaço o principal canal de comunicação e suporte de memória da humanidade a partir do próximo século (LEVY, 1999, p. 93).

Já para Monteiro (2006), o ciberespaço é um novo mundo, um espaço de significações, um meio de interação, comunicação e de vida em sociedade. Ele é real e existe em um plano essencialmente diferente dos espaços conhecidos, localizado em um ambiente cibernético, virtual, abstrato. O que implica em uma nova relação de tempo e espaço, na qual o tempo é real e representado pelo agora.

Deste modo, a internet e o ciberespaço se destacam por transformar a forma como as pessoas se relacionam e comunicam, trazendo uma nova perspectiva para a museologia, possibilitando a construção coletiva de horizontes sociais abertos, dinâmicos e participativos, que permite a multiplicação, em ambiente diferenciado, de emissores, receptores, mensagens e os meios de captação, transmissão e opinião.

As características de imaterialidade, instantaneidade e multimídia da internet, democratiza o acesso à informação, facilita a comunicação entre o público e a instituição museológica e permite uma aproximação estratégica ao eliminar barreiras espaciais, geográficas e temporais (PINHO, 2007, p. 4).

Através da rede, o museu transmite informações atualizadas sobre a instituição, atividades, serviços e programação, ao mesmo tempo que pode permitir o acesso às suas coleções, bibliotecas e recursos educativos, assim como criar lojas online e realizar exposições virtuais (BARBOSA; PORTO; MARTINS, 2012, p. 6).

Além disso, utilizando as redes de informações, várias instituições com objetivos convergentes se conectam e trocam experiências, informações e discussões sobre temas no âmbito da museologia. Este tipo de colaboração permite a criação de laços virtuais e o entrelaçamento de referências patrimoniais.

Assim, o emprego de interfaces colaborativas e equipes multidisciplinares podem proporcionar 
olhares múltiplos sobre o bem cultural. As chamadas interfaces colaborativas podem ser definidas como ambientes virtuais que permitem a comunicação interpessoal entre múltiplos usuários, através da postagem de mensagens, imagens, vídeo ou áudio. Seus usuários e, ao mesmo tempo, produtores, podem ser vistos como um grupo de pessoas que se unem voluntariamente para se comunicar umas com as outras, ou para a realização de uma tarefa que não poderia ser realizada individualmente.

Certamente, o museu rompeu barreiras rígidas no que diz respeito à distribuição e ao acesso à informação, isto é, a fronteira física deixou de ser determinante, e os espaços tornaram-se ambientes dialógicos, interativos, abertos, dinâmicos, com linguagens e recursos técnicos atualizados. Trata-se, portanto, de um momento de transição, redefinição de padrões, de procura por novas linguagens.

É apropriado salientar que o desenvolvimento das mídias sociais possibilita a constante evolução da interação, da partilha e da colaboração, na qual o indivíduo atua como produtor e consumidor de informação.

A difusão de comunidades online, concebidas e mantidas em torno da participação, como o Facebook, o Instagram, o Twitter, o Youtube ou o Second Life, enfatizam o papel do usuário como protagonista na concepção e no desenvolvimento de conteúdos diversos, privilegiando uma relação interativa com os mesmos. Através dessas mídias sociais, o público passa a ser incentivado a participar e a interagir com o museu, que se torna capaz de manter um diálogo virtual personalizado com os seus visitantes, estabelecendo uma relação interativa entre a instituição e a sociedade.

A utilização destas plataformas facilita ao museu obtenção de opiniões, ideias e receber feedback do seu público, também permite partilhar informações sobre o museu e as suas atividades sem os gastos agregados normalmente às ações de promoção ligadas aos canais tradicionais (BERNSTEIN, 2008).

Devido ao impacto e influência da mídia social, torna-se necessário o desenvolvimento de estratégias comunicacionais que possibilitem implementar uma dinâmica contínua no ambiente virtual que permita ao indivíduo a aproximação, consulta e interação com o museu no digital (CARVALHO; RAPOSO, 2012, p. 228).

Atualmente, o museu encontra-se numa encruzilhada de desafios e oportunidades associadas à potencialização da sua comunicação. Neste cenário, algumas instituições museológicas se recusam em aderir as mídias sociais, por diversos motivos, tais como: insuficiência de recursos humanos, tecnológicos e financeiros; ausência de planejamento e a adoção de estratégias de comunicação para gerir o perfil social com regularidade; carência de profissionais que atuam no museu que possuem a competência necessária para coordenar a conta institucional; dificuldade em controlar e monitorar o que é dito neste espaço; resistência em dar voz e ser capaz de compreender e recolher diversos pontos de vista dos públicos.

\section{A interação e a interface}

A interação está na base da experiência do usuário, ela refere-se a maneira como um indivíduo interage com um produto, serviço ou aplicação. Preece, Rogers e Sharp (2013, p. 46) apresentam quatro tipos principais de interação: a instrução, a conversação, a manipulação e a exploração, que serão descritos a seguir de modo mais detalhado.

- Instrução - os usuários emitem instruções a um sistema, dizendo a ele o que fazer. O que pode ser feito, por exemplo, ao digitar comandos, pressionar botões, falar em voz alta e gesticular.

- Conversação - os usuários têm um diálogo com um sistema. Os usuários podem falar por meio de uma interface ou escrever em perguntas para as quais o sistema responde via texto ou saída de voz.

- Manipulação - os usuários interagem com os objetos em um espaço virtual ou físico, manipulando-os. Por exemplo, pode-se mover, abrir, selecionar e fechar objetos digitais. Além disso as ações humanas podem ser imitadas por meio de uso de controladores físicos ou por gestos para controlar os movimentos de um avatar.

- Exploração - os usuários se movem por um ambiente virtual ou um espaço físico. A ideia fundamental é capacitar as pessoas a explorarem e interagirem com um ambiente, seja físico 
ou virtual, por meio da exploração de seu conhecimento sobre como se movem e navegam por espaços existentes.

O Design de Interação (DI) ao estudar o relacionamento entre as pessoas e os artefatos interativos que elas usam, visa facilitar ou fomentar interações entre humanos, por meio de produtos e serviços.

Preece, Rogers e Sharp (2013, p. 8) definem o termo como o ato de criar ou projetar experiências de usuários que melhorem e ampliem a maneira como as pessoas trabalham, se comunicam e interagem. Dessa forma, a essência do DI é a interação que se define pelo contato humano com um sistema através de uma interface.

Na visão de Saffer (2010), o designer de interação deve possuir sete atitudes: focar sempre no usuário; encontrar boas soluções; gerar muitas ideias e buscar uma prototipação rápida; trabalhar de forma colaborativa; criar soluções apropriadas para o contexto; desenvolver com um amplo campo de influências interdisciplinar e incorporar a emoção para seus projetos. O autor também afirma que o usuário é a chave do sucesso no design de interação, e a melhor forma de entendê-lo é questionando suas escolhas e observando suas ações.

Desse modo, o DI almeja encontrar maneiras de propiciar suporte às pessoas e às suas atividades cotidianas por intermédio de uma interface que tenha entendimento imediato, e que proporcione uma interação natural e espontânea (TEIXEIRA, 2014, p. 206).

A interface é um dispositivo que estabelece a comunicação entre dois sistemas distintos, com a função de facilitar e intermediar essa troca de informações para que a tarefa seja executada com eficiência. Ela compreende todos os elementos do sistema com os quais os usuários têm contato física, perceptiva ou conceitualmente (SCHULENBURG; PEZZINI, 2013, p. 200).

Segundo Moraes e Mont'Alvão (2009), a função da interface é facilitar e intermediar a relação interativa entre o homem e a máquina, garantindo que a atenção do usuário seja direcionada na execução da tarefa desejada. Sob o prisma da ergonomia, a interação humana de um sistema é definida como tecnologia projetual das comunicações entre homens e máquinas, trabalho e ambiente. Logo a mediação pode envolver o homem-máquina, homem-ambiente, homem-sistema.

Este sistema aberto proporciona uma experiência individual ao usuário, que se torna agente ativo e ator de comportamento não determinístico. Dificilmente uma interface terá o mesmo significado para dois usuários diferentes, já que cada pessoa é única em sua bagagem de conhecimento e expectativas. As mesmas entradas e saídas do sistema, por exemplo, podem gerar diversas interpretações para pessoas distintas (CYBIS; BETIOL; FAUST, 2010, p. 14).

Desse modo, a interação humano-computador deve ser analisada como uma experiência em constante evolução. Na qual a transformação do ambiente tecnológico é tanto consequência como causa das mudanças de pensamento e comportamento dos usuários, o que torna o desenvolvimento de uma interface um grande desafio.

Conforme Benyon (2011), o design de interface, ao fazer a mediação da interação, preocupase em criar uma experiência que possibilite às pessoas utilizarem, do melhor modo possível, o sistema que é objeto do design. Sendo necessário compreender: o processo sensorial humano; o processo perceptivo; a estrutura dos processos cognitivos; as capacidades e limitações humanas quanto à percepção, memória, raciocínio, planejamento e controles das atividades mentais e emoções.

Segundo Teixeira (2014), o DI utiliza cada vez mais o aspecto lúdico como agente incentivador da exploração da interface do sistema/produto. Assim, visando ampliar a experiência, as interfaces devem ser satisfatórias, agradáveis, divertidas, motivadoras, interessantes, úteis, esteticamente apreciáveis, incentivadoras e criatividade, compensadoras e emocionalmente adequadas às tarefas dos usuários.

As interfaces simples, intuitivas e fáceis de usar fazem com que os usuários se sintam confiantes e satisfeitos por atingirem seus objetivos com menos esforço, em menos tempo e com menos erros. Já as interfaces ruins, na perspectiva dos usuários: dificultam ou impedem o uso de sistema; aborrecem os usuários; são motivos de frustração e perda da autoestima. Além disso, em sistemas de uso frequente e profissional, as frustrações geram a ansiedade e estresse; psicopatologias: irritação, depressão, apatia, posturas negativas, perseguição de colegas (CYBIS; BETIOL; FAUST, 2010, p. 16). 
Muitos adjetivos são empregados para descrever os diversos tipos de interfaces desenvolvidos, tais como gráfico, comando de voz, multimodal, invisível, ambiental, móvel, inteligente, adaptativo, tangível, sem toque e natural. Alguns tem uma função específica, enquanto outros focam o estilo de interação utilizado, o dispositivo de entrada e saída ou a plataforma (PREECE; ROGERS; SHARP, 2013, p.158).

\section{Estudo de caso: Art Project}

Art Project é uma plataforma desenvolvida pela Google, que conta com a colaboração de diversos museus e galerias de arte espalhadas por vários países. Seu objetivo é tornar acessível as obras de arte aos usuários da Internet por meio da web com grande qualidade visual, além de informações sobre as obras e os artistas. A Figura 1 a seguir mostra a página inicial.

Figura 1: Página inicial da plataforma.

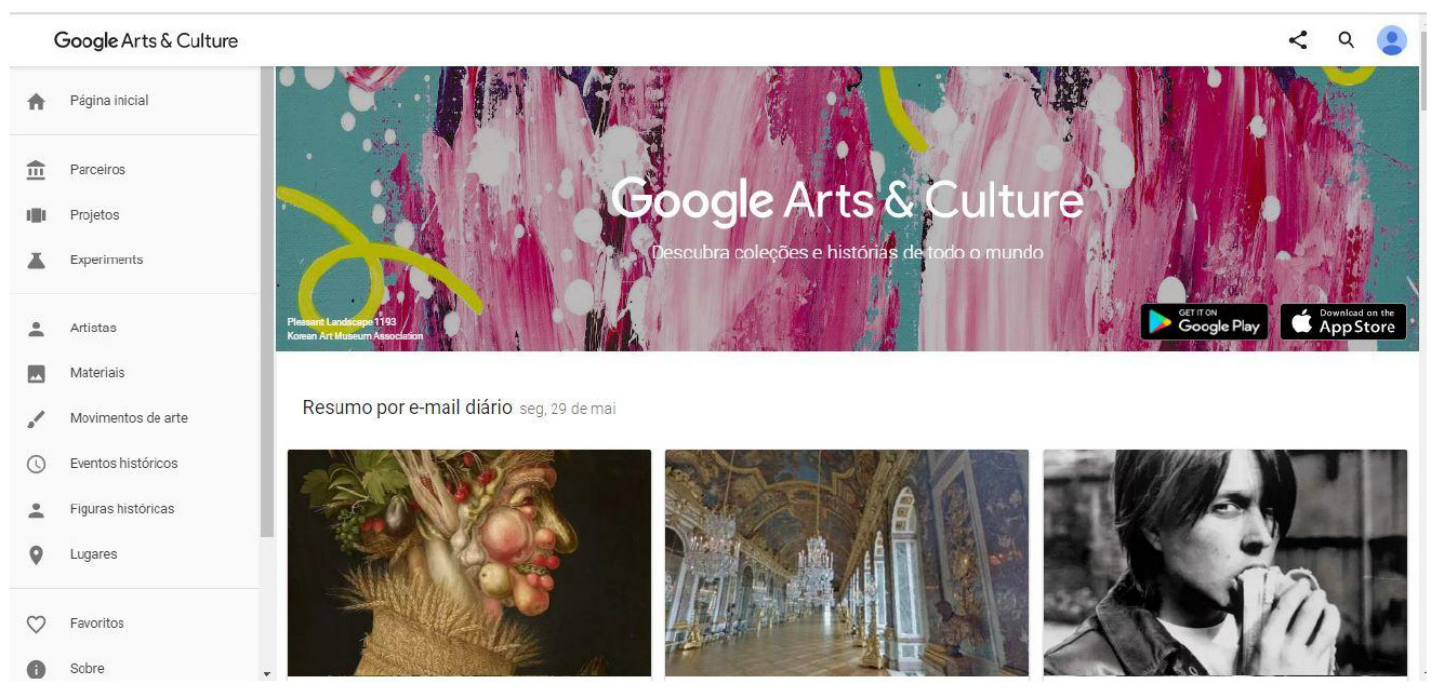

Fonte: www.google.com/culturalinstitute

Lançado em fevereiro de 2011, o projeto reunia disponível em sua primeira versão um acervo com mais de 1000 obras simuladas, envolvendo 17 museus de arte. Em abril de 2012 foi lançada a segunda fase e o número de acervos digitalizados passaram de 17 para 151. Atualmente, ele conta com a parceria de mais de 1.200 museus, galerias e instituições internacionais de 70 países, disponibiliza on-line obras de 6.000 artistas e mais de 6 milhões de artefatos curados. No Brasil, o projeto possui 45 parceiros e disponibiliza virtualmente o acesso a 6.743 itens.

Segundo a empresa idealizadora, a abordagem às instituições museológicas não seguiu qualquer direção curatorial, e cada museu pôde escolher o número de galerias, as obras e as informações que pretendiam disponibilizar.

A interface da plataforma é o meio pelo qual as pessoas e os dispositivos digitais se comunicam, sendo a camada mais próxima do usuário e o ambiente que viabiliza contatos, trocas e comunicação. Esse espaço com o qual o usuário interage no momento da navegação deve ser capaz de instigar e provocar o seu olhar. Além de atrair a atenção, é preciso conduzir o visitante durante a navegação de modo a facilitar a busca da informação. A seguir serão apontadas algumas considerações resultantes da análise da interface da plataforma.

A plataforma possui ferramentas que permitem ao usuário explorar as obras dos catálogos, por meio do sistema de busca por: artistas, materiais, movimentos de arte, eventos históricos, figuras históricas, lugares, parceiros.

A leitura visual da composição se inicia no lado superior esquerdo e dá continuidade até a parte inferior direita. Além disso, o sistema atende à repetição da estrutura das telas em relação às cores, diagramação básica, layout, menu e tipografia. 
No menu superior temos os seguintes ícones: menu lateral; compartilhar, que permite partilhar a informações que o usuário esteja visualizando por meio de diferentes mídias sociais; pesquisar e o perfil do visitante.

Pode- se observar a presença de tons acromáticos: branco, cinza claro e cinza escuro, que não causam fadiga visual. As cores, por sua vez, se concentram nas imagens disponibilizadas pelo sistema de banco de dados. Na página inicial, a separação das informações é discreta, e ocorre a partir das alternâncias de faixas retangulares em tons de cinza claro e branco, evitando que o usuário se confunda com a informação conjunta, o que pode ser observado na Figura 2.

Figura 2: Alternância de tons acromáticos para separação das informações.

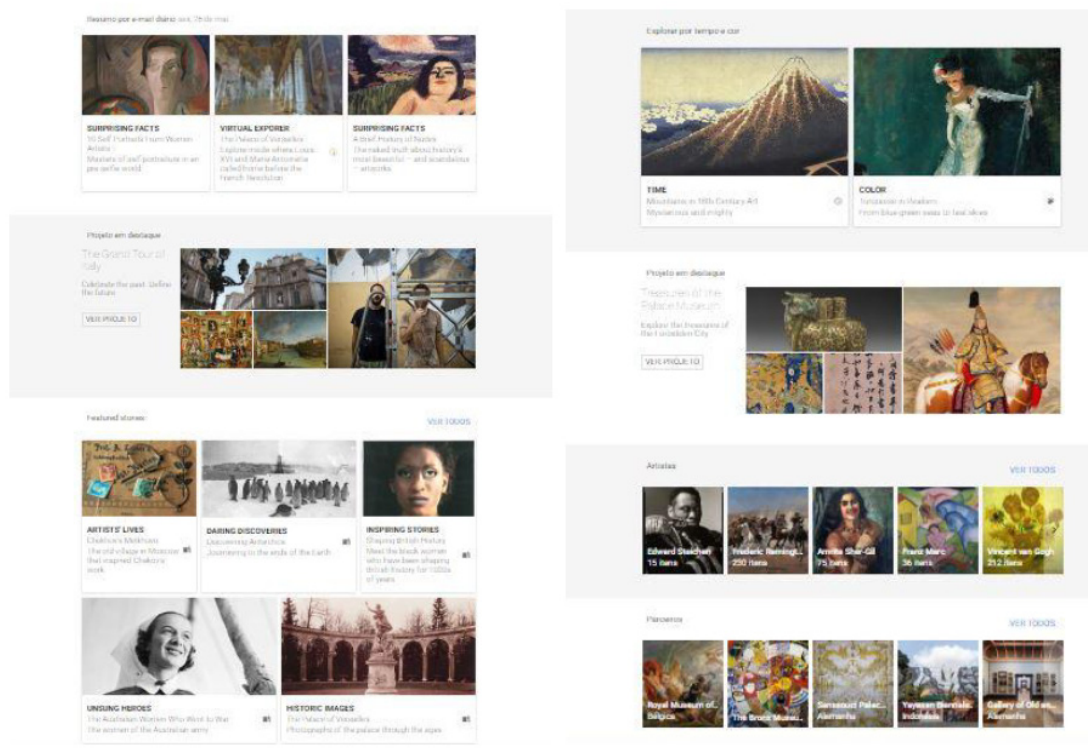

Fonte: www.google.com/culturalinstitute

Dentre as informações disponíveis podemos citar: o resumo diário; projeto em destaque; a ferramenta aumentar zoom; artistas, obras e parceiros; bem como, o acesso a diversos museus através de visitas virtuais.

$\mathrm{Na}$ estrutura da composição nota-se a predominância de formas retangulares e quadriculadas, que se organizam em um sistema proporcional e harmônico. Pode-se inferir que os estudos de grid e da teoria da composição tais como: a regra dos terços, a proporção áurea e os retângulos dinâmicos auxiliaram no desenvolvimento do layout, no qual a malha da construção não se sobressai aos elementos visuais, de modo a garantir movimento de dinamismo da composição.

As tipografias sem serifas adotadas são constantes no projeto, sendo adequada para o sistema digital. Observa-se a predominância do utilizo de caixa baixa em relação a caixa alta; há espaçamento de caracteres; e o espaçamento entrelinhas apresenta-se de forma compreensível.

Com relação ao conteúdo disponibilizado, na página de parceiros é possível conhecer as instituições envolvidas. A análise foi direcionada para o Brasil, o projeto conta com 45 parceiros nacionais, que se concentram principalmente na região sudeste.

Em Minas Gerais se encontram apenas dois colaboradores: o Instituto Inhotim e o Instituto Terra. O Instituto Inhotim é localizado em Brumadinho e destaca-se por sua coleção de arte e de botânica; já o Instituto Terra é uma ONG localizada em Aimorés, que atua na restauração de áreas degradadas de Mata Atlântica e na recuperação das fontes de água da região banhada pela Bacia Hidrográfica do Rio Doce.

Para aprofundar a análise foi selecionado o primeiro museu moderno no país: o Museu de Arte de São Paulo Assis Chateaubriand, conhecido MASP. Hoje sua coleção reúne mais de 8 mil obras, incluindo pinturas, esculturas, objetos, fotografias e vestuário de diversos períodos e origens. Além da exposição permanente do acervo, são realizadas exposições temporárias, cursos, palestras, apresentações de música, dança e teatro. 
Na página referente à essa instituição é possível: obter informações básicas; ler um resumo descritivo do local; conhecer as exposições disponíveis e os mais de 1.006 itens digitalizados; ver sua localização geográfica e realizar uma visita virtual.

Ao selecionar uma exposição o visitante é reportado a uma outra interface, cujo formato se assemelha a de um catálogo ou revista digital. Nas páginas desse documento, que são passadas ao se clicar as setas localizadas nas laterais, o usuário é conduzido por uma narrativa que contextualiza a obra exposta; sendo possível ampliar, reduzir e mover as imagens mostradas.

Ao clicar sobre um dos itens disponibilizados, uma nova janela se abre. Nela encontra-se a imagem da obra centralizada e os detalhes referentes a ela, tais como: nome, data, técnica, dimensões, autor, procedência e tipo. Ao clicar no ícone da lupa é possível ampliar a imagem e observar detalhes antes imperceptíveis.

Para explorar virtualmente o espaço digitalizado da instituição, o visitante dever clicar sobre o pegman (boneco amarelo), sendo direcionado a uma outra página, como mostra a Figura 3, na qual pode locomover se através do mouse ou das setas direcionais do teclado. Para se localizar no espaço existe o link que direciona para a planta do museu, sendo possível escolher o local e o pavimento a ser explorado.

A visita virtual desse espaço permite a interação, a navegação e a visualização de um local real, através de uma janela que os usuários podem controlar de forma interativa. Apesar da baixa interatividade da experiência, se essa transcorre através de meios não imersivos, a visita online permite planejar a visita real, ao possibilitar que o usuário conheça a disposição e o conteúdo do acervo.

Desse modo, no ambiente virtual o visitante pode escolher uma trajetória por todo o local mapeado clicando sobre os links para outras imagens panorâmicas, com a possibilidade de zoom nos detalhes de seu interesse.

Figura 3: Interface inicial da visita virtual ao MASP e a planta espacial.

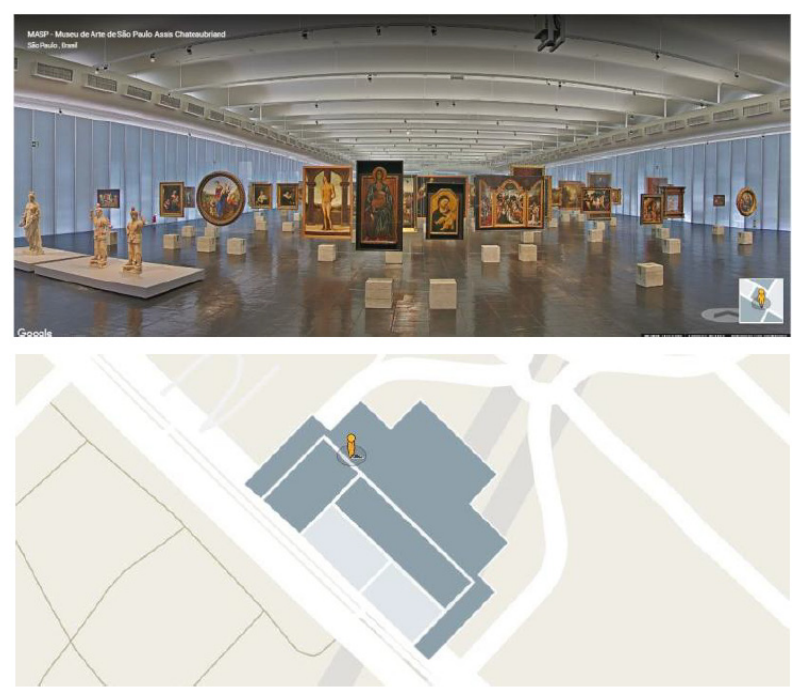

Fonte: www.google.com/culturalinstitute

O desenvolvimento da plataforma Art Project e dos museus virtuais envolvem o emprego de diversas tecnologias, tais como: o Google Maps, Google Earth, Street View, dispositivos de captura e processamento de imagens, entre outros.

O Google Maps é um serviço gratuito de pesquisa e visualização e mapas na web, que pode ser usado online e offline, que permite aos usuários encontrar endereços específicos, verificar trajetos, identificar o seu local, medir distâncias entre dois ou mais pontos, caminhar virtualmente por diferentes locais, visualizar imagens de satélite.

O Google Earth é um programa de computador cuja função é apresentar um modelo tridimensional do globo terrestre, construído a partir de um mosaico de imagens de satélite obtidas de fontes diversas, como imagens aéreas e GIS 3D. Esse mapa em três dimensões viabiliza passeios virtuais, gera mapas bidimensionais, simula diversas paisagens, e possibilita identificar distintos locais 
e seus elementos. Dentre as funções oferecidas destacam-se: a ferramenta explorar que consenti ao usuário navegar pela região com a visão do alto ou da rua; os cartões de reconhecimento com o resumo das informações locais; o voo 3D que possibilita observar o local de vários ângulos; o voyager que direciona a visita de acordo com temas e o botão estou com sorte.

O Street View utiliza computadores, softwares, câmeras, sensores, lasers e sistemas de posicionamento global (GPS), sendo uma tecnologia que mescla a fotografia e a interface de navegação espacial, de modo a disponibilizar vistas panorâmicas de $360^{\circ}$ na horizontal e $290^{\circ}$ na vertical. Tal recurso permite ao usuário encontrar localidades, ver as ruas por mapa ou imagem via satélite, se movimentar virtualmente pelo percurso e ver pontos de referência através de fotos que permitem a visualização em $360^{\circ}$, além de obter instruções de rotas.

O sistema é capaz de capturar nove imagens ao mesmo tempo a cada 10 metros, por meio de nove câmeras, oito alinhadas horizontalmente e uma com lente olho de peixe no topo. Os sensores e o GPS armazenam as informações de distância e a localização das imagens que são gravadas em discos rígidos no computador, que possui um sistema para organizar todos os dados capturados. As imagens capturadas são posteriormente montadas formando uma única imagem panorâmica.

De acordo com as informações disponibilizadas pela Google, inicia-se o processo com a coleta de imagens. Para o registro fotográfico é necessário estar atento a muitos fatores, tais como as condições climáticas e a densidade populacional de diversas áreas, para determinar qual o melhor horário e local para a coleta.

$\mathrm{Na}$ etapa de alinhamento de imagens, para corresponder cada imagem com sua respectiva localização geográfica no mapa, são combinados sinais de sensores do carro que calculam os dados do GPS, velocidade e rota. Esses recursos auxiliam na reconstrução do trajeto exato e até mesmo se necessário inclinar e realinhar as imagens.

Para evitar falhas nas fotos $360^{\circ}$, câmeras adjacentes tiram fotos levemente sobrepostas, esses registros são agrupados lado a lado e curvadas, formando uma imagem panorâmica cilíndrica. Nessa fase, são aplicados algoritmos especiais de processamento de imagens para diminuir as "costuras" e criar uma transição suave. Com o intuito de garantir que seja mostrada a imagem correta é utilizado o scanner $3 \mathrm{~d}$ que funciona com um sonar. Ele emite feixes de laser do carro que refletem nas superfícies, e no retorno eles são captados por sensores. Esse tempo de reflexão e retorno dos feixes informa a distância entre o carro e o objeto, e possibilita a transformação da informação em um mapa 3D que é associado às fotos.

Para acessar a visualização tridimensional no Google Maps, deve-se selecionar a opção Street View e mover o ícone pegman (boneco amarelo) até o espaço que se deseja observar. O programa permite ao usuário se deslocar para frente e para traz e rodar em $360^{\circ}$, através das setas direcionais. Quando o usuário se afasta para uma área distante, o modelo 3D determina o melhor panorama daquele local a ser mostrado.

As fotografias panorâmicas utilizadas no desenvolvimento da interface, são tiradas na superfície por diferentes meios, tais como: Google car, carros adaptados; Trike, triciclo com um sistema de câmeras no alto recolhe automaticamente as imagens à medida que o operador pedala; Trekker, mochila equipada com um sistema de câmeras no topo e sua portabilidade permite coletar imagens em espaços apertados e estreitos ou locais acessíveis apenas a pé; Trolley; carrinho com dimensões reduzidas com um sistema de câmeras, que podem ser visualizados na Figura 4.

Figura 4: As imagens mostram respectivamente: o Google Car, o Trekker, o Trike e o Trolley.
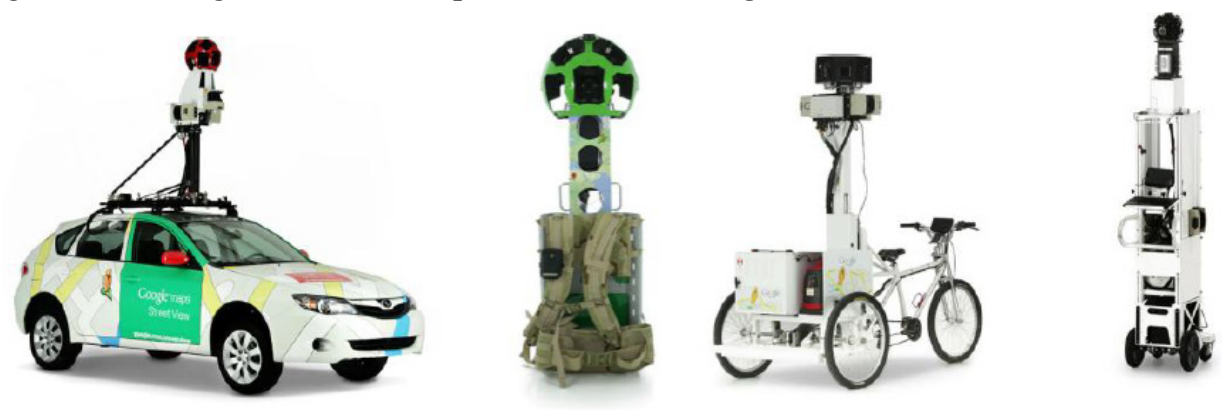

Fonte: www.google.com/culturalinstitute 
Para se adequar aos espaços físicos dos museus e galerias, de modo que fosse possível capturar por meio de fotografias digitais os espaços e as obras de arte, o sistema tecnológico da Street View foi adaptado a uma estrutura de carrinho denominada trolley. Esse carrinho tem aproximadamente com 2,6 metros de altura e pesa $60 \mathrm{~kg}$, possui 15 câmeras, um computador com tela e teclado para processar e armazenar as fotos e três lasers que detectam a profundidade das salas dos museus, o que é útil para detectar as dimensões de um quadro.

O trolley percorre os corredores dos museus e contorna facilmente as obras de arte, é por meio dela que se captura as imagens necessárias e suas localizações no espaço para se construir os modelos em três dimensões, como ilustra a Figura 5.

Figura 5: As imagens ilustram o trolley percorrendo as salas dos museus.

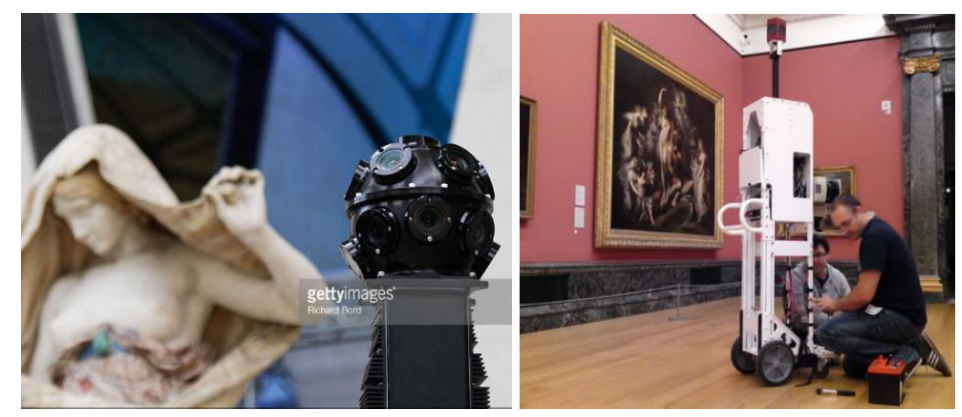

Fonte: www.google.com/culturalinstitute

A Google também desenvolveu a Art Camera, retratada na Figura 6, uma câmera capaz de registrar imagens em giga pixel, ou seja, compostas por mais de um bilhão de pixels. Desse modo, ele permite registrar obras de arte nos mínimos detalhes e ver detalhes invisíveis a olho nu. O dispositivo é conduzido automaticamente por cada detalhe, gerando centenas de imagens em alta resolução das telas. Para garantir o foco correto, a câmera é equipada com laser e sonar, que usa alta frequência de som para medir a distância em relação ao quadro. Quando os detalhes desejados são compreendidos pela câmera, os softwares do Google tiram centenas de fotos em close de cada um deles, até cobrir toda a pintura. Após fotografar todos os pontos em super zoom, esses mesmos programas unem as partes e compõem uma imagem única de ultra alta resolução.

Figura 6: Utilização da Art Camera para captura de imagens.

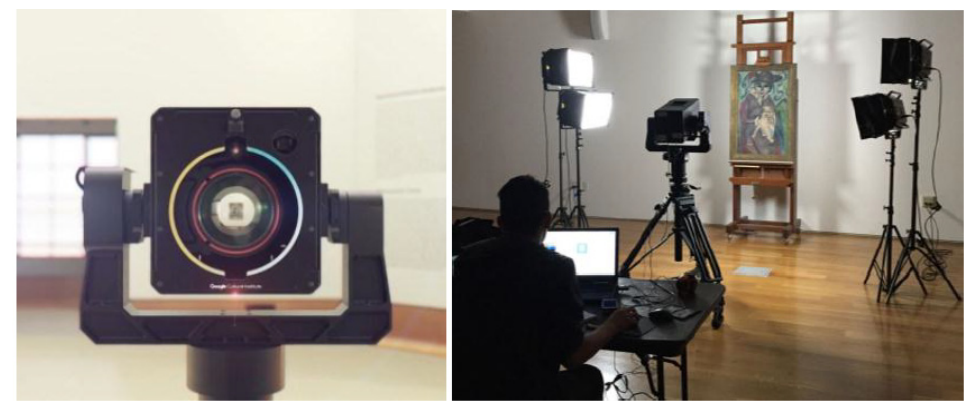

Fonte: www.google.com/culturalinstitute

O aplicativo Arts \& Culture, por sua vez, disponibiliza imagens, vídeos, textos e ferramentas para pesquisar obras de arte por qualquer palavra-chave. A Figura 7 mostra algumas interfaces do aplicativo. Ele possibilita: as visitas virtuais imersivas, por meio da utilização do Google Cardboard; os passeios de Street View, no qual o usuário toca com os dedos a tela do dispositivo para passear pela exibição; a visualização das obras com o Zoom Views; e a identificação de obras no visor da câmera através do recurso Art Recognizer.

Além disso, o aplicativo permite: ver os trabalhos de artistas evoluir ao longo do tempo; procurar por tempo e cor as obras de arte, filtrando-as por cor ou período; salvar as obras de arte 
favoritas, em uma coleção pessoal e compartilha-la com amigos; encontrar museus e eventos culturais ao seu redor e a fazer visitas guiadas com especialistas.

Figura 7: Interfaces do aplicativo Arts \& Culture.
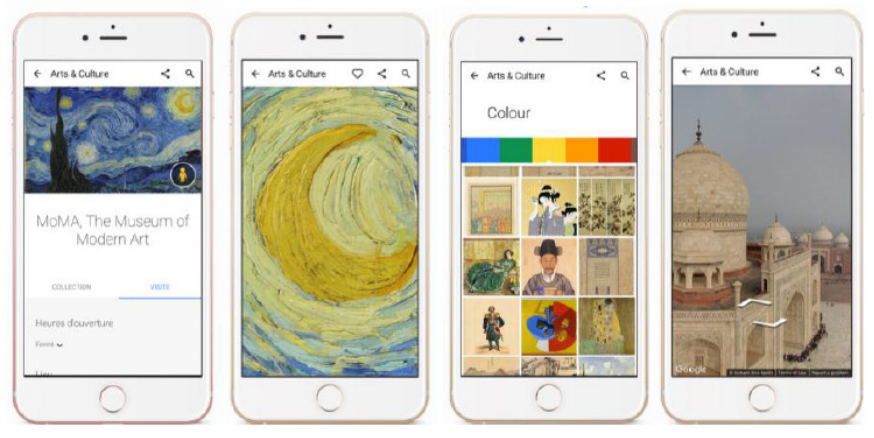

Fonte: techcrunch.com

A seguir serão apresentados alguns projetos experimentais desenvolvidos por criadores e artistas em parceria com o Google Arts \& Culture, que visam ampliar a experiência do usuário ao navegar entre a arte tecnologia.

- Tags - o experimento explora à aprendizagem automática e pode ajudar as pessoas a navegar nas obras de arte de forma semelhante à pesquisa na web, ou seja, trata-se de uma espécie de explorador. Usando um algoritmo empregado na busca do Google Imagens, a máquina analisou as imagens das obras de arte e gerou mais de 4.000 palavras chaves que são combinados no sistema de busca. A Figura 8 mostra algumas das palavras geradas.

Figura 8: Exemplos de palavras chaves utilizadas no sistema de busca.
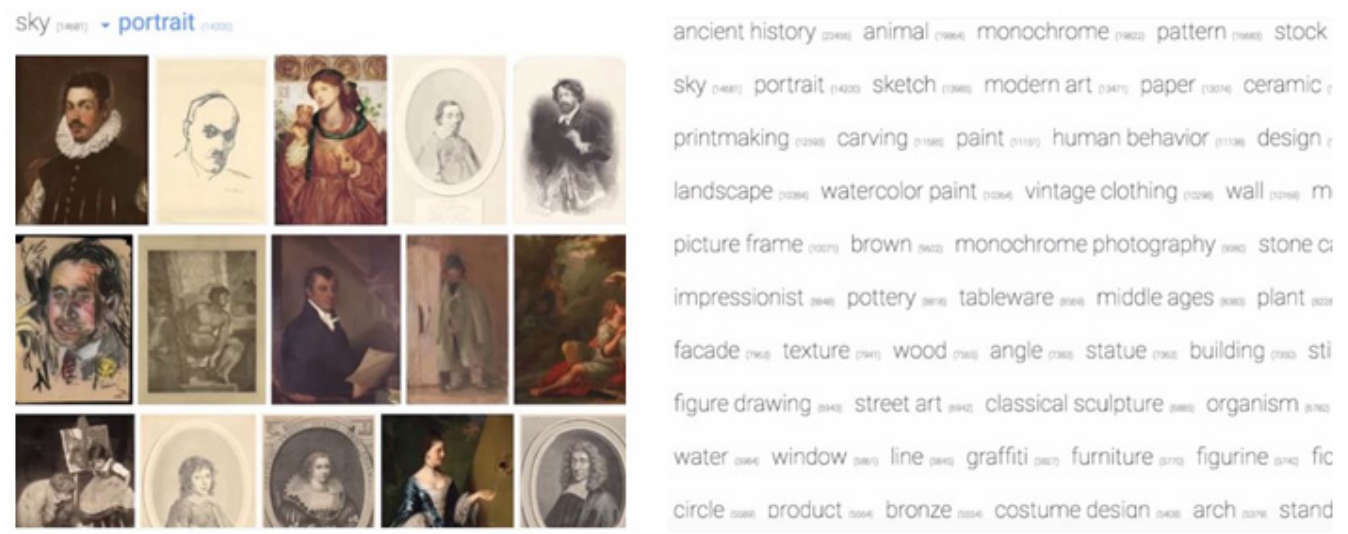

Fonte: artsexperiments.withgoogle.com

- Free fall - são empregadas fórmulas matemáticas para desenvolver um espaço tridimensional onde as obras são disponibilizadas. Nesse ambiente virtual, o usuário interage com as obras e identifica padrões em escala. Ele pode optar por visualizar algo como um big bang cultural, ou por navegar através do mar de obras de arte década a década. As obras são animadas em tempo real no navegador usando WebGL e com resoluções de até $1024 \mathrm{px}$, graças ao préprocessamento de dados e aos mecanismos de níveis de detalhe.

- Curator table - Inspirado por curadores em todo o mundo, a equipe aplicou o princípio de colocar impressões em uma mesa ao planejar uma exposição, para a galeria virtual. Por meio de uma mesa de curador virtual é possível descobrir novos insights e conexões entre obras de 
arte. Os recursos são animados em tempo real e é possível pesquisar objetos, estilos e artistas e visualizá-los em um espaço 3D.

- X Degrees of separation - usando técnicas de aprendizagem automática que analisam as características visuais de obras de arte, o sistema encontra conexões entre dois artefatos, conectando-os através de uma cadeia de obras de arte. Essa rede de obras conectadas permite $\mathrm{X}$ graus de separação e conduz a uma rota cênica onde são apresentadas relações surpreendentes entre obras de artistas consagrados e desconhecidos, e a beleza dos artefatos.

- Tsne map - permite ao visitante virtual explorar uma paisagem 3D interativa criada por algoritmos de aprendizagem automática que organiza as obras de arte por similaridade visual. Quanto mais semelhantes duas obras de arte, mais próximas elas estarão. A similaridade visual é calculada com um algoritmo de imagem de computador usado na busca do Google com base puramente nas imagens. Em seguida, é aplicado o algoritmo t-SNE, geralmente usado para depurar imagens estáticas, para criar um espaço virtual interativo que ao usuário navegar e olhar para obras de arte de qualquer ângulo e escala.

Por fim cabe mencionar os estudos de Mesquita (2016) que propõem um sistema de signos em forma de camadas, como mostra o Quadro 1, para analisar o Art Project. Segundo o autor, os sistemas de base são formados pelo sistema computacional, pelas tecnologias de captura de imagens em $360^{\circ}$, pelas instituições culturais e museológicas. Eles produzem a informação necessária para os demais níveis comunicativos. O sistema computacional é um conjunto de diversos dispositivos, tais como: processador, memória, discos, sistema operacional e dispositivos de entrada e saída de dados que atuando em conjunto fazem o computador, o tablete e o smartphone funcionarem.

Quadro 1: Sistemas de signos organizados em forma de camadas.

\begin{tabular}{|c|c|}
\hline Sistemas de superfície & $\begin{array}{c}\text { Códigos visuais, verbais e } \\
\text { audiovisuais. }\end{array}$ \\
\hline Sistemas intermediários & HTML, Javascript, Actionscript \\
\hline Sistemas de base & $\begin{array}{c}\text { Street View, museus físicos, } \\
\text { sistema computacional }\end{array}$ \\
\hline
\end{tabular}

Fonte: Elaborado pelas autoras, baseado na imagem de MESQUITA, 2016, p. 91.

Os sistemas intermediários são formados pelas linguagens de programação (HTML, Javascript e Actionscript) que são ferramentas utilizadas para o desenvolvimento de softwares, por meio de conjunto de instruções lógicas e matemáticas, que definem as ações de um programa, aplicativo ou site.

O usuário requisita o arquivo que contém o código da página do Google Art Project por meio do seu browser, que é um programa de armazenado no computador composto por uma série de rotinas descritas pelo código do programa para o qual, entre outras funções, cumpre o papel de permitir o carregamento de páginas de hipertexto e a comunicação com o servidor por meio da interface da rede (MESQUITA, 2016, p.105).

Já os sistemas de superfície são constituídos pelos códigos visual, verbal, audiovisual e sonoro, que são responsáveis por comunicar a informação no museu virtual. Esses códigos formam a interface, com a qual o usuário estabelece contato, no nível mais superficial e aparente. Desse modo, as imagens, os vídeos e os textos fornecem informações das obras e artistas que compõem a galeria virtual dos museus.

Para Mesquita (2016), os sistemas mantem relações desde o nível mais superficial até a base, sendo o museu virtual resultado de um processo dialógico entre sistemas semióticos distintos, 
desempenhando cada sistema um papel no processo comunicativo. Na relação entre os recursos tecnológicos e os museus físicos, a visita virtual é resultante dos processos de tradução dos modelos reais em imagens digitais. Após a captura das imagens, que se dá nos espaços dos museus físicos, elas são processadas por meio de software específicos para a construção das panorâmicas.

Em seguida, são inseridos códigos das linguagens de programação para proporcionar interatividade nas imagens digitais panorâmicas e construir a interface do site. Assim, a partir das linguagens do HTML, javascript e actionscrip do flash são trabalhadas a interatividade e os recursos que permitem a visita virtual $360^{\circ}$. A Figura 9 mostra os elementos que compõem a visita virtual. Desse modo o museu virtual se configura como um espaço formado por uma rede complexa de sistemas que funcionam em dependência uns com os outros.

Figura 9: Elementos que compõem a visita virtual do Art Project.

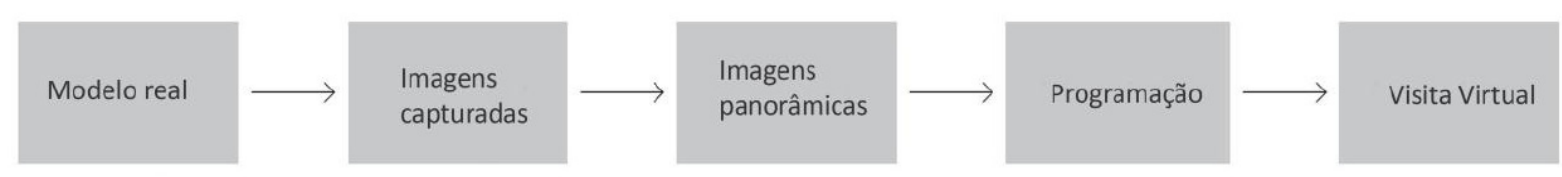

Fonte: Elaborado pelas autoras, baseado na imagem de MESQUITA, 2016, p. 118.

\section{Considerações finais}

Historicamente, os museus têm sido flexíveis na adoção de posturas e configurações favoráveis ao desenvolvimento social e humano, refletindo os contextos socioculturais em que estão inseridos. Observa-se que, atualmente, aos museus tradicionais estão se transformando na era digital.

Ao utilizar a rede como meio de se comunicar e difundir os seus espaços, os museus têm aplicado diversas ferramentas, em prol de fluxos dinâmicos e que atraiam, cada vez mais, visitantes. $\mathrm{O}$ museu, portanto, torna-se um espaço aberto, de comunicação que almeja atender à função do homem como indivíduo e como ser social.

Com a expansão da rede, multiplicaram-se sites de Museus, dedicados aos mais diferentes temas, com nomes e tipologias. Essa capacidade de alcance possibilitada pela web chegou a despertar o questionamento de que os museus físicos pudessem ser substituídos por seus equivalentes digitais.

Contudo, cabe ressaltar que as novas formas de museus existentes no ciberespaço não substituem os originais, mas somam-se a elas, estabelecendo novas relações. Dessa forma, a visita presencial deve ser valorizada, já que a experiência estética do contato direto com o bem cultural não se pode reproduzir no ambiente digital.

O estudo aprofundado do Art Project ajudou a compreender: sua origem, as tecnologias empregadas, os sistemas que o constituem, seu processo de desenvolvimento e confirmou a relevância desse projeto como um grande museu virtual por reunir em um ambiente virtual diversos espaços físicos virtualizados e possibilitar diversos níveis de interação entre as obras e o espaço virtual.

Por tudo que foi abordado, conclui-se que as TICs abrem novas perspectivas para os museus, ao possibilitar o acesso a manifestações, a criações culturais, permitindo experiências únicas no âmbito digital. 
Virtual museum: space of interaction

\section{abstract:}

The development, consolidation and diffusion of Information and Communication Technologies drove a culture revolution that has fostered profound changes in society, both in the speed of connection of technologies and in the transformation of production, storage, distribution and access to information models. In this context, the virtual museum emerges, as fruit of the dialogue between museological practices and the new technologies. These spaces with varied formats and objectives are composed of a collection of digitized objects, organized and displayed in a logical way. Connectivity and accessibility allow the visitor to transcend traditional modes of communication, providing a dynamic vision and an interactive contact with the collection and the exhibition space. Thus, focusing on the material and immaterial cultural heritage, the virtual museum uses interactivity and immersive techniques with learning and research objectives for the entertainment and appreciation of the visitor experience. This article has an exploratory driver and uses as technical procedure bibliographic survey and a case study. It addresses definitions of physical and virtual museums, cyberspace, interaction, and examines how museums have broken down strong barriers to distribution and access to information. Moreover, it comprises a case study of the Art Project is carried out, its origin, the technologies employed, its constituting the systems, and its development process. The analysis confirms the relevance of the project as a large virtual museum that brings together in one environment several virtualized physical spaces and allows the interaction between the works, the virtual space and the visitor.

\section{keywords:}

virtual museum; technology; Art Project; interaction.

\section{Referências bibliográficas}

BARBOSA, Cátia R.; PORTO, Renata M. A. B; MARTINS, Cesar E. M. A. Museus: sistemas de informação para uma realidade virtual. In: XIII Encontro Nacional de Pesquisa em Ciência da Informação, 2012, Rio de Janeiro. Anais do XIII ENANCIB, Rio de Janeiro, 2012.

BENYON, David. Interação humano-computador. 2. ed. São Paulo: Pearson Prentice Hall, 2011.

BERNSTEIN, Shelley. Where do we go from here? Continuing with Web 2.0 at the Brooklyn Museum. In:Museums ant the web 2008. Québec: Archives \& Museum Informatics.

CANOVA, Diana. Digitalizzazione 3D dei beni culturali e murei interattivi. Il caso del Museu Archeologico di Milano. 2015. 227f. Monografia (Design da Comunicação) - Politecnico di Milano, Milão, 2015.

CARVALHO, Joana; RAPOSO, Rui. O potencial do social media como ferramenta de comunicação dos museus com o seu público através do digital. Revista Comunicando, v.1, n.1, dez. 2012, p. 212 233.

CASTELLS, Manuel. Os museus na era da informação: conectores culturais de tempo e espaço. In: BARRANHA, Helena; MARTINS, Susana S.; RIBEIRO, A. P. (Org.) Museus sem lugar: ensaios, manifestos e diálogos em rede, Lisboa, 2015. p. 47-63.

CASTELLS, Manuel. A galáxia Internet: reflexões sobre Internet, negócios e sociedade. Lisboa: Ed. Fundação Calouste Gulbenkian, 2001.

CASTELLS, Manuel. A sociedade em Rede: a era da informação - economia, sociedade e cultura. v.1. São Paulo: Paz e Terra. 2000. 
CYBIS, Walter; BETIOL, Adriana Holtz; FAUST, Richard. Ergonomia e usabilidade:

conhecimentos, métodos e aplicações. 2 ed. São Paulo: Novatec, 2010.

HENRIQUES, Rosali. Museus virtuais e cibermuseus: A Internet e os museus. Lisboa. 2004. LÉVY, Pierre. Conexões planetárias: o mercado, o ciberespaço, a consciência. São Paulo: ed.34, 2001.

LÉVY, Pierre. Cibercultura. 2 ed. São Paulo: Ed. 34, 1999.

LOUREIRO, Maria Lucia N. M. Museus de arte no ciberespaço: uma abordagem conceitual. 2003. 208 f. Tese (Doutorado em Ciência da Informação) - Universidade Federal do Rio de Janeiro, Rio de Janeiro, 2003.

MAGALDI, Monique. Navegando no museu virtual: um olhar sobre formas criativas de manifestação do fenômeno museu. 2010. 209 f. Dissertação (Mestrado em Museologia e Patrimônio) - Universidade Federal do Estado do Rio de janeiro, Rio de Janeiro, 2010.

MESQUITA, Walter. Semioses na web: os processos comunicativos do google art project. 1 ed. Curitiba: Appris, 2016.

MONTEIRO, Silvana. O ciberespaço e os mecanismos de busca: novas máquinas semióticas. Ciência da Informação, n. 35, ago. 2006.

MUCHACHO, Rute M. S. P. Museus virtuais: a importância da usabilidade na mediação entre o público e o objeto museológico. In: IV Congresso da Associação Portuguesa de Ciências da Comunicação, 2005, Aveiro. Anais ... Aveiro, Portugal: Comissão Editorial da Universidade de Aveiro, 2005, p. 15401547.

PREECE, Jennifer; ROGERS, Yvonne; SHARP, Helen. Design de interação: além da interação humano-computador. 3 ed. Porto Alegre: Bookman, 2013.

PINHO, Joana Maria B., 2007, Museus e internet. Recursos online nos sitios web dos museus nacionais portugueses. Revista Textos de la CiberSociedad, n. 8, Temática Variada. Disponível em: <http://www.cibersociedad.net> Acesso em: maio 2016.

SAFFER, Dan. Designing for Interaction: creating innovative applications and devices .2 ed. Berkeley: New Riders, 2010.

SCHULENBURG, Roy; PEZZINI, Marina R. Sistematização de conceitos ergonômicos e semióticos para projetos de interfaces gráficas do usuário. Revista Projética, Londrina, v. 4, n. 1, p.199-218, jan. /jun. 2013.

SCHWEIBENZ, Werner. Le musée virtuel. ICOM News dedicated to Virtual Museums, v. 57, n.3, 2004, p. 3.

TEIXEIRA, Eduardo A. S. Design de interação. 1 ed. Rio de Janeiro: 5W, 2014. 